\title{
Mechanical Properties of Wood Plastic Composites with the Activated Wood Filler
}

\author{
Galia Shulga \\ Latvian State Institute of Wood \\ Chemistry \\ Riga, Latvia \\ shulga@junik.lv \\ Anrijs Verovkins \\ Latvian State Institute of Wood \\ Chemistry \\ Riga, Latvia \\ anrivero@inbox.lv
}

\author{
Brigita Neiberte \\ Latvian State Institute of Wood \\ Chemistry \\ Riga, Latvia \\ bricis46@inbox.lv \\ Julia Brovkina \\ Latvian State Institute of Wood \\ Chemistry \\ Riga, Latvia \\ yuli@inbox.lv
}

\author{
Sanita Vitolina \\ Latvian State Institute of Wood \\ Chemistry \\ Riga, Latvia \\ sanita.vitolina@gmail.com \\ Talrits Betkers \\ Latvian State Institute of Wood \\ Chemistry \\ Riga, Latvia \\ betalrits@gmail.com
}

\begin{abstract}
The aim of the research was a study of the effect of activation of birch sawdust microparticles with a dilute solution of sodium hydroxide at a low temperature on mechanical properties and water sorption of the obtained wood plastic composite (WPC) samples obtained from a byproduct of a domestic wood mechanical processing and a recycled polymer municipal waste. It was found that the mechanical (tensile, bending) properties of the WPC samples filled with the activated birch sawdust microparticles were higher than those of the samples filled with the initial sawdust. The sorption and swelling degree of the WPC samples with the activated filler were lower than those for the samples with the initial sawdust. However, the difference in the values of the water sorption and the swelling degree for the samples filled with the activated and initial wood microparticles were relatively low in comparison with the observed essential difference in their mechanical properties. This fact was explained by the enhanced content of carbonyl groups in the activated sawdust microparticles that are able to absorb water.
\end{abstract}

Keywords - mechanical properties, recycled polypropylene, wood-plastic composite, wood surface activation

\section{INTRODUCTION}

The increasing focus on eco-friendliness, such as the European Union's directives, has led to greater challenge for the development of commercially viable biodegradable composites. Due to the renewability, easy availability, low cost and biodegradability of lignocellulose, its usage as a filler in wood-plastic composites (WPCs) containing two main components - a lignocellulosic filler and a thermoplastic polymer is very promising and perspective [1-2]. WPCs are a young generation of composites with rapidly growing usage within the plastics industry. Such type of composite materials responds to (semi)bio-composites, because a content of a wood filler in them can achieve 70-80 wt\%. Their global market is increasing at a very rapid pace, and is predicted to exceed 10 billion dollars by 2026. WPCs find wide application for producing of decking and decorative materials for building engineering, in auto industry, for production of domestic and technical items, etc. It is known that reducing the concentration of atmospheric carbon dioxide is a fundamental challenge for the twenty-first century. In this connection, EU sets out ambitious targets towards to recycling and recovery of polymer wastes, preventing their leakage into the environment as well accelerating their usage efficiency [3]. Evidently that the practice for development of WPCs based on recycled polymers in a more extent is gained by the growing awareness of environmental problems and the importance of energy conservation.

The main problem for all WPCs is a low interfacial adhesion between a polymer matrix and a wood filler that negatively affects the WPC performance properties [4-5]. A strong adhesion at the polymer/wood interface is 
needed for an effective transfer of stress and load distribution throughout the interface as well as for the prevention of fibre-fibre interaction leading to agglomeration of wood particles. This is a challenge for the development of effective functionalization methods for a wood particles surface. There are many various physical (corona, plasma) and chemical methods (mercerisation, acetylation, benzylation, amination, graft copolymerisation, treatment with acids, peroxide, various anhydrides, permanganate, silane, etc.) for wood functionalisation as a filler, which are able increasing the interfacial adhesion in WPCs via strengthening physicochemical interaction between a polymer matrix and a wood surface [6-9].

Alkaline treatment is one of the most commonly used chemical treatments of lignocellulosic fibres for improving compatibility at the polymer/filler interface in WPCs [10-11]. During alkali treatment, the destruction of hydrogen bonding in the lignocellulosic matrix network occurs. This leads to the increase in an amorphous cellulose content and surface roughness of lignocellulosic fibres as well as causes the disintegration of bundles of the fibres, reducing their sizes. Additionally, extracts and wax are removed from the cell wall too. In such a manner, the alkali treatment increases the availability of a wood surface for interfacial interaction with a polymer matrix during their thermal processing.

It is known that the alkaline treatment is carried out using the enhanced concentrations of alkali solutions at high temperatures. However, very scarce information is available about the effect of wood fibres treated with a low concentration alkali solution at a moderate temperature on the WPCs properties.

In this research the effect of the activation of birch wood sawdust with a low concentrated alkali solution at a low temperature on the mechanical and water sorption properties of recycled polymer-based wood-plastic composite was investigated.

\section{MATERIALS AND METHODS}

\section{A. Materials}

All the initial materials for fabricating a new WPC are represented the Latvian origin wastes. The birch wood sawdust was a by-product of the Latvian wood processing company. The main part of its fractional composition consisted of wood particles with a size between 250 and $500 \mu \mathrm{m}$. The sawdust was characterized by elemental analysis (ElementarAnalysensysteme $\mathrm{GmbH}$, Germany) and wood polymers composition according to Klason and Kürschner chemical procedures for lignin (TAPPI 20022003) [12] and cellulose (TAPPI 1999) [13], respectively, as well as hemicelluloses (TAPPI 1997) [14].

Recycled polypropylene (rPP) $\left(0.9 \mathrm{t} / \mathrm{m}^{3}, 5.2 \mathrm{~g} / 10 \mathrm{~min}\right.$ at $230{ }^{\circ} \mathrm{C}$, and $2.16 \mathrm{~kg}$ ) was produced from municipal polypropylene wastes at a Latvian polymer recycling plant (Nordic Plast Ltd., Latvia) and used as a thermoplastic polymer matrix.

\section{B. Methods}

Milling. For obtaining a fraction less than $100 \mu \mathrm{m}$, both the initial and activated birch sanding dust were milled and sieved. Milling was carried out with a planetary ball mill (Retsch, Germany) at 300 min-1 during $15 \mathrm{~min}$. The fractionation was performed by using Pulverizette 0 (Fritsch, Germany) during 30 min.

Conductometric titration. The conductometric titration was used for determination of a total content of acidic groups in the sawdust samples. The curves of water suspensions of the initial and alkaline sawdust microparticles were obtained using InoLab level 3 Multiparameter Meter (WTW, Germany) at their constant stirring at $25^{\circ} \mathrm{C}$. $0.1 \mathrm{~mol} / \mathrm{dm}^{3} \mathrm{HCl}$ solution was used for the adjustment of $\mathrm{pH}$ values.

Water sorption and swelling. The water sorption and swelling of the composite samples were determined after their full immersion in distilled water for 16 days at room temperature according to ASTM D 570-98. Water adsorption (WA) amount as calculated using the following formula:

$$
\mathrm{WA}(\%)=\left(\mathrm{m}_{\mathrm{o}}-\mathrm{m}_{\mathrm{t}}\right) / \mathrm{m}_{\mathrm{o}} \times 100,
$$

where $m_{o}$ and $m_{t}$ were the initial oven-dry weight and weight after time $t$, respectively.

By recording the changes in the thickness (T) of the samples over a given period of time (t) and applying it to the thickness of the dry sample, the degree of swelling (SW) was calculated.

$$
\operatorname{SW}(\%)=\left(T_{t}-T_{0}\right) / T_{0} \times 100,
$$

where $T_{o}$ and $T_{t}$ were the initial thickness and thickness after time t, respectively.

Mechanical tests. Mechanical properties were determined with a universal machine "Zwick" (Zwick/Roell, Germany) with a load capacity of $0.5 \mathrm{kN}$ at a rate of $50 \mathrm{~mm} / \mathrm{min}$ and $2 \mathrm{~mm} / \mathrm{min}$ for tensile and bending tests, respectively, according to ASTM D638 (ASTM 2007) and EN ISO 178 (EN ISO 2003) with the help of the software program TestXpert. Before testing, the samples were conditioned at $60^{\circ} \mathrm{C}$ during $24 \mathrm{~h}$. Five replicates were made for each mechanical testing, and the standard deviation for each index was found.

Transmission electron microscopy (TEM). The shape of the dust particles was measured by transmission electron microscopy (Leo 912 AB Omega microscope, Germany).

Scanning electron microscopy (SEM). The morphology of the obtained WPC samples was examined using a scanning electron microscope (Tesla, Czech Republic).

Differentialthermal analysis (DTA). Thermal stability was determined using a thermal analyser "PerkinElmer" at a heating rate of $50 \mathrm{C}$ under a nitrogen atmosphere.

Alkaline treatment. To activate birch wood sawdust, alkaline treatment was carried out by using a 5-L threeneck flask equipped with a return condenser, a thermometer and a stirrer under the following conditions: $\mathrm{NaOH}$ concentration of $0.025 \mathrm{~g} / \mathrm{dl}$, temperature $60^{\circ} \mathrm{C}$ and duration $5 \mathrm{~h}$ at a hydromodulus (sawdust/water mass ratio) of $1 / 20$. After the treatment, the activated sawdust was washed, dried and milled for obtaining microparticles 
less than $100 \mu \mathrm{m}$. For comparison of the activation effect, the initial sawdust was also milled, and its fraction less than $100 \mu \mathrm{m}$ was used.

Preparation of WPC samples. Before obtaining the WPC samples, the powdered rPP and the sawdust microparticles were mixed for 3 min at room temperature, using an electrical mechanical grinder. The samples for tensile and bending tests were prepared by the extrusion and moulding method using HAAKE MiniLab II and MiniJet II (Thermo Fisher Scientific, Germany) at a temperature of $175^{\circ} \mathrm{C}$, a circulation time in the two-screw extruder of $5 \mathrm{~min}$, and a moulding pressure of $45 \mathrm{MPa}$ at a temperature of $120{ }^{\circ} \mathrm{C}$. The content of the sawdust microparticles in the WPC samples varied from $10 \mathrm{wt} \%$ to $50 \mathrm{wt} \%$.

\section{RESULTS AND DISCUSSION}

\section{A. Characteristic of activated sawdust microparticles}

The initial birch sawdust had the following elemental composition: $48.1 \%$ C, 5.93\% H, $45.7 \% \mathrm{O}$ and $0.26 \% \mathrm{~N}$. The alkaline treatment resulted in a slight decrease in the carbon content $(47.7 \%)$ and a slight increase in the oxygen content $(46.3 \%)$. A content of the main wood components of sawdust particles before and after their alkaline treatment is presented in Table 1. According to the chemical analysis, the activated sawdust contains a little more cellulose (Cel), but a slightly less lignin (Lig) and hemicellulose (HC). The treatment with the dilute sodium hydroxide solution leads to the remarkable increase in the amount of acidic groups (phenolic hydroxyl, carboxyl) $\left(\mathrm{OH}_{\mathrm{tit}}\right)$ and carbonyl (CO) groups (almost two times) and to the slight decrease in the content of methoxyl groups $\left(\mathrm{OCH}_{3}\right)$ that indicated the activation of the surface of the wood sawdust microparticles.

TABLE 1. CHEMICAL COMPOSITION OF INITIAL AND ACTIVATED BIRCH SAWDUST

\begin{tabular}{|l|c|c|c|c|l|c|}
\hline \multirow{3}{*}{ Sample } & \multicolumn{3}{|c|}{$\begin{array}{c}\text { Wood components, } \\
\text { \% }\end{array}$} & \multicolumn{3}{c|}{$\begin{array}{c}\text { Functional } \\
\text { composition, \% }\end{array}$} \\
\cline { 2 - 7 } & $\mathbf{C e l}$ & Lig & HC & OCH $_{3}$ & $\boldsymbol{O H}_{\text {tit }}$ & CO \\
\hline initial & 50.2 & 21.8 & 23.5 & 5.7 & 10.4 & 2.1 \\
\hline activated & 51.7 & 20.3 & 22.4 & 5.5 & 13.3 & 3.9 \\
\hline
\end{tabular}

Scanning electron microscope images of the initial and activated milled sawdust are shown in Fig. 1. The images clearly indicate the distinction in fibres dimensions of these sawdust samples.

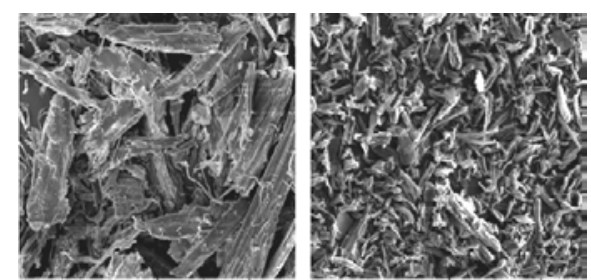

Fig. 1. Fig.1. SEM images of initial and activated milled sawdust (x 500)
The TEM micrographs of the activated sawdust microparticles $(<100 \mu \mathrm{m})$ (Fig. 2) shown the presence of two shapes of the microparticles. The oval particles has an average diameter of 2-3 $\mu \mathrm{m}$, but the extended ones have a length of 4-6 $\mu \mathrm{m}$ and a width of $0.5-1.5 \mu \mathrm{m}$, respectively. Their low length and low aspect ratio between the width and the length indicated a short fibre nature of the activated microparticles.

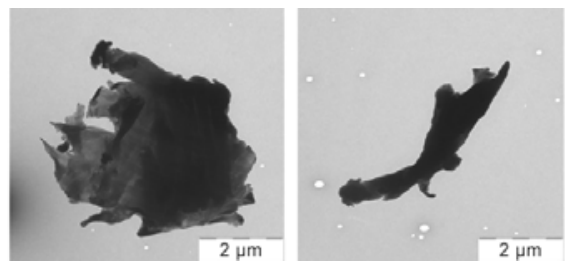

Fig. 2. TEM micrographs of the activated sawdust microparticles

Since the fabricating of WPC samples occurs at high temperatures, it was interest to study a thermal stability of the activated wood. Fig. 3 shows the thermogravimetric (TGA), differential gravimetric analysis (DTG), and differential thermal analysis (DTA) curves for the activated sawdust microparticles. According to the obtained curves, the mass losses of the activated sawdust at a temperature of $170^{\circ} \mathrm{C}-180^{\circ} \mathrm{C}$, which is the processing temperature of WPC samples in the extruder and moulding machine, do not exceed $8 \pm 2 \%$ by weight (for the initial sawdust $-7 \pm 2 \%$ ), and are mainly related to the residual moisture content in the activated sawdust. This means that the alkaline activation of the birch sawdust does not reduce its thermal stability.

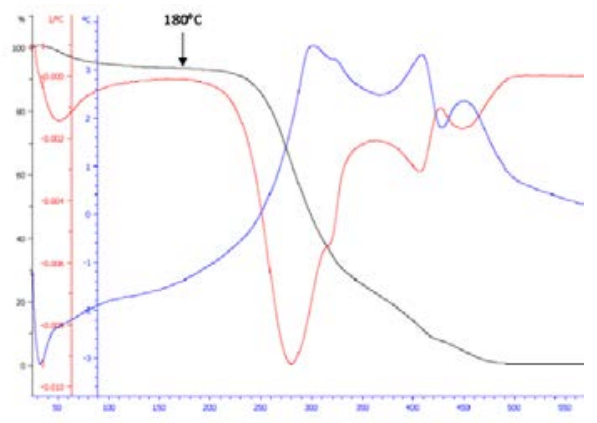

Fig. 3. TGA, DTG un DTA curves of the activated wood sawdust

\section{B. Properties of WPC samples}

The composite raw blends were prepared by mixing rPP powder with the initial and activated birch sawdust microparticles less than $100 \mu \mathrm{m}$ using an electrical mechanical grinder. The mechanical properties of rPP and the rPP-based composite samples filled with the initial and activated birch wood microparticles with a filling from $10 \mathrm{wt} \%$ to $50 \mathrm{wt} \%$ are shown in Fig. 4-7. It can be seen that the mechanical properties of the obtained WPC samples filled with the activated microparticles are much higher than those of the samples filled with the initial sawdust microparticles and the recycled polymer. 


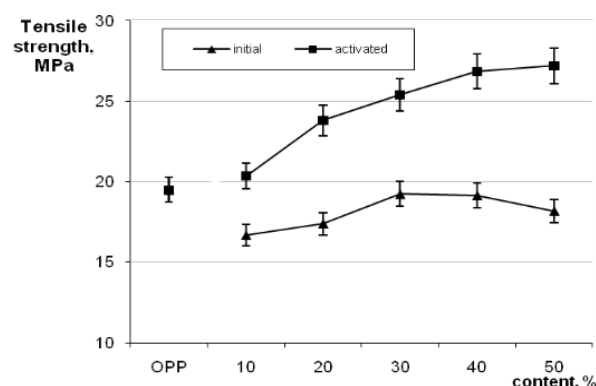

Fig. 4. Tensile strength of WPC samples filled with the activated and initial sawdust

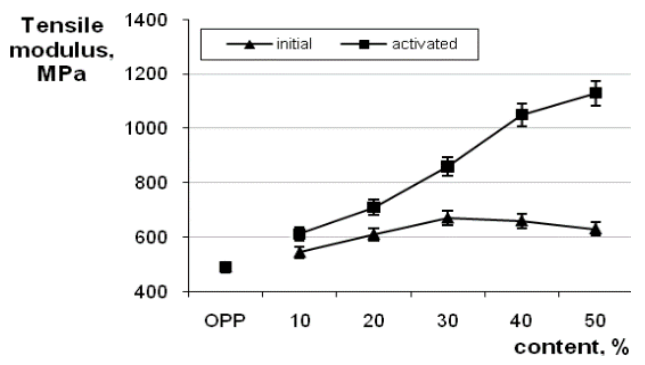

Fig. 5. Young's modulus of WPC samples filled with the activated and initial sawdust

As shown Fig. 4 and Fig. 5, the values of ultimate tensile strength and Young's modulus for the samples with the activated wood microparticles ranged from 20.4 MPa to 27.2 MPa and 613 MPa to $1300 \mathrm{MPa}$, respectively, with increasing a content of the filler from $10 \mathrm{wt} \%$ to $50 \mathrm{wt} \%$. The given results indicate a pronounced improvement of the mechanical parameters of the WPC samples filled with the activated microparticles, compared with the case of recycled PP. The ultimate tensile strength and Young's modulus of the samples incorporating the activated microparticles increases almost 1.3 and 2 times, respectively, at $50 \%$ filling. At the same time, the samples containing the initial sawdust were characterised by lower values of the ultimate tensile strength in comparison with rPP.

The dependences of bending strength and bending modulus on the content of the initial and activated wood particles are shown in Fig. 6 and Fig. 7. It can be seen that, with increasing the content of both initial and activated microparticles, the bending strength and bending modulus grow and are higher than those of the rPP values. The values of bending strength and bending modulus for the samples with the activated wood microparticles ranged from 22.5 $\mathrm{MPa}$ to $29.1 \mathrm{MPa}$ and $1256 \mathrm{MPa}$ to $2707 \mathrm{MPa}$, respectively, but for the samples with the initial sawdust varied from 21.8 MPa to 25.3 $\mathrm{MPa}$ and $1054 \mathrm{MPa}$ to $2105 \mathrm{MPa}$ with increasing a content of the particles from $10 \mathrm{wt} \%$ to $50 \mathrm{wt} \%$. The bending strength and the bending modulus of the samples incorporating the activated and initial microparticles increase almost 3.0 and 2.3 times, respectively, at 50\% filling. Simultaneously, the deformability of these composites essentially decreases, namely, elongation at break dropped 5 and 2 times, but deflection ability diminished more than 4 and 2 times for the samples with the initial and activated sawdust, respectively, in comparison with the case of the initial recycled polymer. This may indicate the enhanced stiffness of the obtained WPC samples.

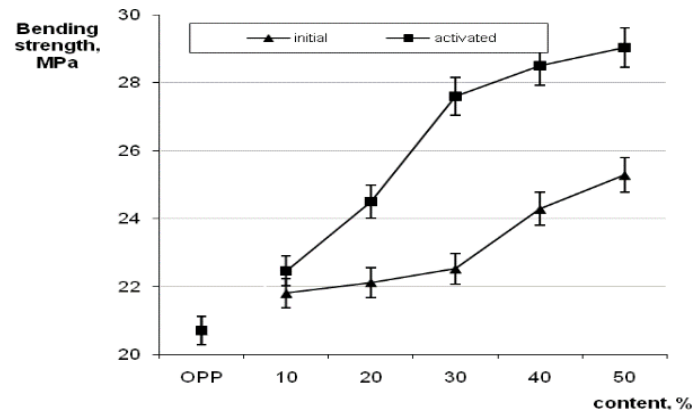

Fig. 6. Bending strength of WPC samples filled with the activated and initial sawdust

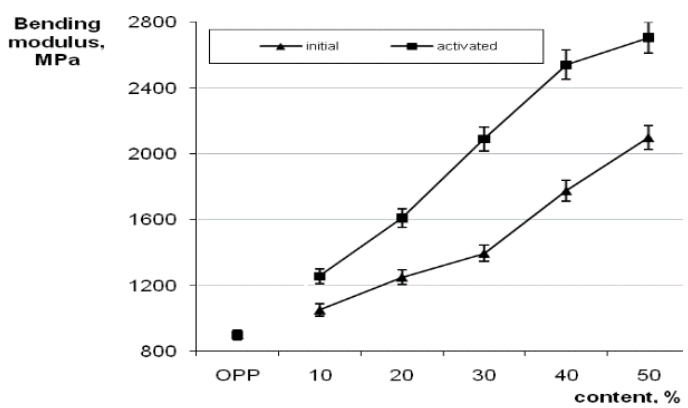

Fig. 7. Bending modulus of WPC samples filled with the activated and initial sawdust

Evidently, the appearance of the added amount of the acidic groups such as phenolic at the wood particles' surface by its treatment with the dilute alkaline solution promotes the interaction at the polymer matrix/wood filler interface due to the possible formation of a hydrogen linkages network between the oxygen-containing groups at the filler surface and the hydroxyl groups of the recycled $\mathrm{PP}$ in the composite processing, which can lead to the partial structuring of the interfacial layers. These factors favour the compatibility between the polymer matrix and the filler in the complex system. Lower indicators of the mechanical properties for the samples with the initial sawdust microparticles were attributed to the insufficient interface adhesion between the phases.

It is known that the ability of WPCs to uptake water vapours during exploitation can negatively affect their mechanical strength, dimensional stability, and resistance against biological decay [15, 16]. Fig. 8 and Fig. 9 demonstrate the results of a study of the water sorption and swelling degree of the composites, which were obtained for 4, 8, 12 and 16 days. For this purpose, the samples were totally immersed in distilled water at room temperature. It can be seen that the sorption and swelling degree of the composites with the activated filler are lower than those for the sample with the initial sawdust. 


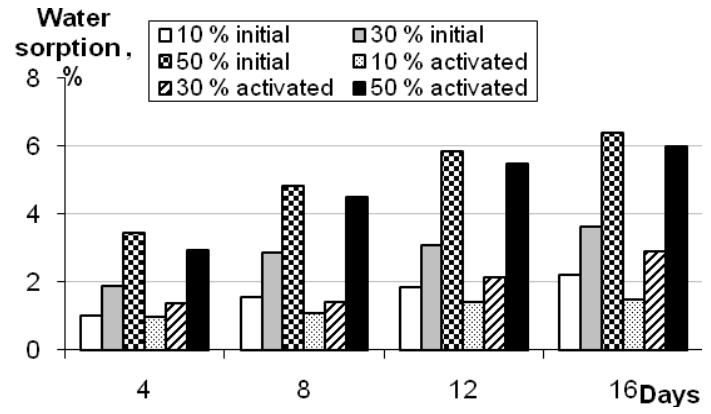

Fig. 8. Water sorption of WPC samples filled with the activated and initial sawdust

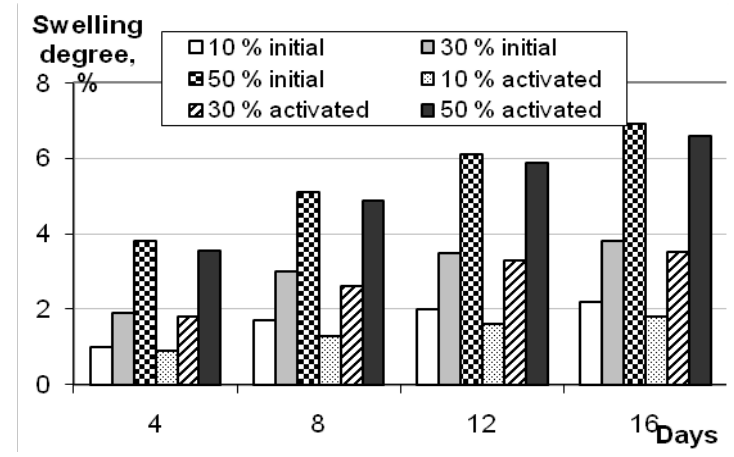

Fig. 9. Swelling degree of WPC samples filled with the activated and initial sawdust

With increasing the time of the test, the water uptake grows achieving $6.4 \mathrm{wt} \%$ и $6.0 \mathrm{wt} \%$ for the WPC samples containing the $50 \%$ initial and $50 \%$ activated sawdust microparticles, respectively, after 16 days of their immersion in water. The values of the swelling degree for these samples after the end of the test are $6.9 \%$ and $6.6 \%$, respectively. The highest gain in the weight and the thickness is characteristic for the samples containing the maximum amount of the sawdust microparticles, while at a filling of $30 \mathrm{wt} \%$, the values of the water uptake and the swelling degree after 16 days do not exceed $2.9 \mathrm{wt} \%$ and $3.5 \%$, respectively, for the samples with the activated sawdust, and $3.5 \mathrm{wt} \%$ and $3.8 \%$, respectively, for the samples with the initial microparticles. The relatively low difference in the values of the water sorption and the swelling degree for the samples filled with the activated and initial wood microparticles in comparison with the observed essential difference in their mechanical properties may be explained by the enhanced content of the carbonyl groups in the activated sawdust, which were able to absorb water. No other hand, this may indicate the fact that the same method of functionalization of the wood surface does not always has the same effect on both mechanical and wetting properties of the WPC samples.

\section{CONCLUSIONS}

Thus, using the by-product of a domestic wood mechanical processing and the recycled municipal polymer waste, the new wood-plastic composite has been obtained. It was characterised by the enhanced mechanical properties and stiffness in comparison with the properties of the composite filled with initial sawdust. The insufficient water resistance of the obtained WPC filled with the activated sawdust particles was explained by the enhanced content of carbonyl groups in the activated sawdust.

\section{ACKNOWLEDGMENTS}

The authors would like to thank the Ministry of Education and Science of the Republic of Latvia for the financial support of the institute's grant “AtkritBiomasKM”.

\section{REFERENCES}

[1] K. L. Pickering, M. A. Efendy, T. M. Le, A review of recent developments in natural fibre composites and their mechanical performance, Compos. Part A- Appl. S., 2016, 83, pp. 98-112.

[2] O. Faruk, A. K. Bledzki, H.-P. Fink, M. Sain, Biocomposites reinforced with natural fibers: 2000-2010, Prog. Polym. Sci., 2012, 201237(11), pp. 1552-1596.

[3] J. Korhonen, A. Honkasalo, J. Seppälä, Circular economy: The concept and its limitations, Ecol. Econ. 2018, 143, 37-46.

[4] M. Farsi, Effect of surface modification on thermo-mechanical behaviour of wood-polymer composite, Asian J. Chem., 2012), 24(6), pp. 2775-2779.

[5] K. L. Pickering, M. A. Efendy, T. M. Le, A review of recent developments in natural fibre composites and their mechanical performance, Compos. Part A-Appl. S., 2016, 83, pp. 98-112.

[6] M. J. John, R. D. Anandjiwala, Recent developments in chemical modification and characterization of natural fibre-reinforced composites, Polymer Composites, 2008, 29(2), pp. 187-194.

[7] K.G. Satyanarayana, G.G.C. Arizaga, F. Wypych, Biodegradable composites based on lignocellulosic fibers, An overview, Progress in Polymer Science, 2009, 34, pp. 982 -998.

[8] G. Shulga, B. Neiberte, A. Verovkins, S. Vitolina, J. Jaunslavietis, J. Ozolins, Short fibre filler from wood residue for polymeric composite materials, Mater. Sci. (Medžiagotyra), 2016, 22(3), pp. 370-375.

[9] X. Li, L.G. Tabil, S. Panigrahi, Chemical treatments of natural fiber for use in natural fiber-reinforced composites, Journal of Polymers and the Environment, 2007, 15, pp. 25-28.

[10] J. Lin, Z. Yang, X. Hu, G. Hong, S. Zhang, Wei Song, The Effect of Alkali Treatment on Properties of Dopamine Modification of Bamboo Fiber/Polylactic Acid Composites, Polymers, 2018, 10, pp.1-12.

[11] G. Rajesh, AVR. Prasad, Effect of fibre loading and successive alkali treatments on Tensile properties of short jute fibre reinforced polypropylene composites. Advanced Materials Manufacturing and Characterization, 2013, 3, pp. 528-535.

[12] TAPPI T203 cm-99 (1999). "Alpha-, beta- and gamma-cellulose in pulp,” TAPPI Press, Atlanta, GA, USA.

[13] TAPPI T222 om-02 (2002). “Acid-insoluble lignin in wood and pulp,” TAPPI Press, Atlanta, A, USA.

[14] TAPPI T264 om-97 (1997). "Preparation of wood for chemical analysis,” TAPPI Press, Atlanta, GA, USA.

[15] R. M. Taib, Z. A. M. Ishak , H. D. Rozman, W. G., Glasser, Effect of moisture absorption on the tensile properties of steamexploded Acacia mangium fiber-polypropylene composites, J. Thermoplast. Compos. Mater., 2006, 19(5), pp. 475-489.

[16] A. Fortini, V. Mazzanti, Combined effect of water uptake and temperature on wood polymer composites: Research Article. J. of Applied Polymer Science, 2018, 135(5): 46674, pp. 1-9. 